\title{
DAMSAT: An eye in the sky for monitoring tailings dams
}

\section{Darren Lumbroso, Marta Roca Collell, Gregor Petkovšek, Mark Davison, Ye Liu, Craig Goff, Mark Wetton}

HR Wallingford, Howbery Park, Wallingford, Oxfordshire OX10 8BA, UK Corresponding author: Darren Lumbroso, d.lumbroso@hrwallingford.com

This is a pre-print of an article published in the Mine Water and the Environment Journal in September 2020

The final authenticated version is available online at: https://doi.org/10.1007/s10230-020-00727-1

\section{Abstract}

During the past decade, there have been a number of catastrophic tailings dam failures. Affordable monitoring systems, as well as methods to assess the risk posed to communities living downstream of these structures, are needed. In recent years the availability and accuracy of remote sensing information has increased, whilst its cost has decreased.. This paper provides an overview of DAMSAT, a web-based system that brings together Earth Observation and other data to help governments and mining companies monitor tailing dams, and estimate the downstream risks they pose. The methods developed are being piloted in Peru at a number of tailings dams, with the overall goal of improving the decision making process and sharing of information with respect to managing these structures. Engagement with Peruvian stakeholders has shown that DAMSAT provides tools that can help government authorities both reduce the risks and increase the sustainability of mining.

\section{Introduction}

Transparency in the extractive sector is needed to improve governance, reduce corruption, prevent environmental harm, and capture the benefits of mining within countries whose economies are reliant on it (Ayee et al. 2011; Condon 2017; Leonard 2017; Sachs and Warner 2001; Palú and Julien 2019). The origins of the movement towards transparency date back to the late 1990s and the need to put an end to resource conflict and, what has come to be known as, the "resource curse" (Sachs and Warner 2001). The sudden discovery of precious resources in low income countries can trigger conflict when the wealth generated is concentrated in the hands of a small number of people (Dale 2019; McDevitt 2017); this has led to violence in a number of countries including Mozambique, Nigeria, Sierra Leone, and Peru. A review of 52 empirical studies found that industrial mining was frequently linked to increased poverty in low income countries (Gamu et al. 2015). Over the long term, research has found a strong relationship between mineral wealth and a decline in democracy in low income countries with fragile governments (Dale 2019). Much of the solution to the resource curse can be found in increased transparency and accountability (Dale 2019).

Many governments in low income, and some high income countries, lack the technical expertise and resources that large mining companies have (Aguirregabiria and Luengo 2016; Franks 2015). This makes it 
challenging for environmental regulators and governments to hold mining companies to account. The wage differences between government and multinational mining corporations, as well as the industry-wide dependence on specialist environmental engineering consultancies, inhibits transparency (Franks 2015). This often prevents effective government and third-party evaluation of the environmental risks posed by mines (De Carvalho 2019; Franks 2015). Governments also face the challenge of overseeing many mines, often in remote locations, with limited numbers of staff, who are often less experienced than those employed by the mines they are regulating (Lumbroso et al. 2019).

Large multinational firms often account for the greatest volume of revenue from mining in low income countries; however, they often do not account for most of the mining footprint. Instead, a multitude of "junior" mining companies work on small to medium sized sites, operating on exceptionally tight budgets, with limited reputational risk (Ledwaba and Nhlengetwa 2016). The junior mining sector faces a number of challenges including access to finance for capital intensive prospective field mining projects, as well as very high economic and technical risks (Mulaba-Bafubiandi and Singh 2018).

In 2001, the International Commission on Large Dams (ICOLD) criticised the mining industry's record on tailings dam failures (ICOLD 2001); however, in the past 20 years the number of significant tailings dams accidents has remained high. A spate of catastrophic tailings dam failures in recent years have killed thousands of people, done great environmental harm, and damaged people's livelihoods (Lumbroso et al 2019). On 25 Jan. 2019, the Barragem 1 tailings dam, which stored 11.7 million $\mathrm{m}^{3}$ of tailings at the Mina Córrego de Feijão in the Minas Gerais region of Brazil, failed, resulting in the deaths of about 300 people and the pollution of hundreds of kilometres of river downstream of the site (Cambridge and Shaw 2019; Vergilio et al. 2020). This was the fifth major failure of a tailings dam in this region of Brazil in the past 18 years (Cambridge and Shaw 2019). In 2015, the Fundão tailings dam failed. It was also located in Minas Gerais and resulted in 19 fatalities, pollution of the water supply for hundreds of thousands of people, as well as a $20 \%$ increase in dengue fever in the affected communities (Agurto-Detzel et al. 2016; Nishijima and Rocha 2020). Planning for this disaster was found to be inadequate, with no response plan in place, no effective alarm system, and no quantitative or qualitative description of the worst-case scenarios (De Carvalho 2019).

The Brazilian Government has recently passed legislation that requires regular inspection of tailings dam, which have been "effectively self-auditing to date and the regulator is recognised as having inadequate resources to provide oversight of the new regulations given the large stock of at-risk tailings dams in Minas Gerais" (Cambridge and Shaw 2019). In addition, in many countries, environmental regulators often do not know where all the tailings dams are located. Recent work by Oxford University, which used remote sensing data together with machine learning, has to date found three major tailings dams that were previously unknown to the Brazilian National Audit Office (O'Neill 2019).

There are also thousands of abandoned tailings dams throughout the world. These are often the result of junior mining operations, which if they do not "strike it rich" before their debt is due, may have no choice but to file for bankruptcy and abandon their mining operations, leaving a legacy of "orphaned" tailings dams (Lumbroso et al. 2019). There is also some evidence to suggest that the data on tailings dam failures is incomplete, with many smaller accidents going unreported for a variety of reasons, including because mine managers are afraid of taking legal responsibility (Bowker, and Chambers 2016, 2017; Davies 2002;).

To improve the transparency of mining operations, there is a need to reduce the cost and improve the way in which many tailings dams are monitored, especially where there are thousands of these structures spread over a wide area. Over the last 10 years, there has been an increase in the coverage and accuracy of 
remote sensing data from satellites (UN 2017), a trend that should continue (Marcuccio et al. 2019). This paper presents a system, known as DAMSAT, which uses a variety of Earth Observation (EO) data to improve the transparency and accountability of the mining industry with regards to tailings dam management. DAMSAT is an applied research project, which was funded by a grant from the U.K. Space Agency's International Partnership Programme, aims to demonstrate the advantages of using EO based technologies. A consortium of organisations, named in the acknowledgements, have collaborated to develop methods based on remote sensing data to monitor and assess the risks posed by various aspects of tailings dams. These methods are currently being piloted in Peru. This paper summarizes these methods and how they can be used to improve risk assessments and tailings dam monitoring.

\section{Types of tailing dams and their potential problems}

There are three main ways in which tailings dams are constructed (Fig. 1):

1. Upstream construction - This is the most cost effective method, due to the minimal amount of material needed for the initial construction and subsequent raisings; however, they are "unforgiving structures" vulnerable to failure as a result of any one or combinations of improper design, construction, and operation (Martin and McRoberts 1999).

2. Downstream construction - This method minimises the chance of breaching due to its structural stability because no wet tailings are stored below the embankment. It is also the most expensive construction method because it requires a larger area and more material.

3. Centreline construction - This is an intermediate solution in terms of costs and volume. In this method, the centre lines of the embankments coincide as the tailings dam is raised.

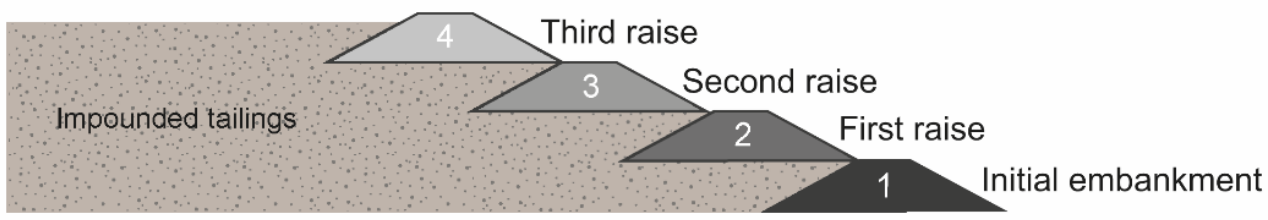

\section{Upstream construction method}

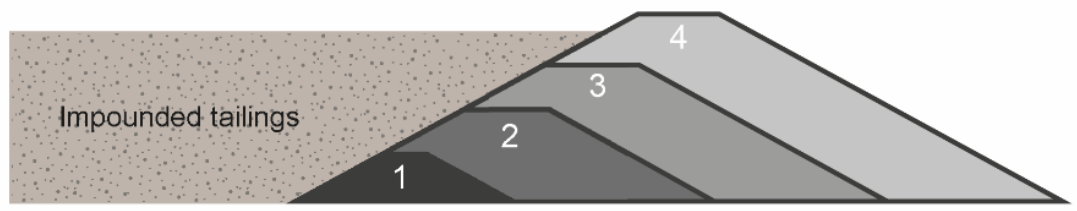

Downstream construction method

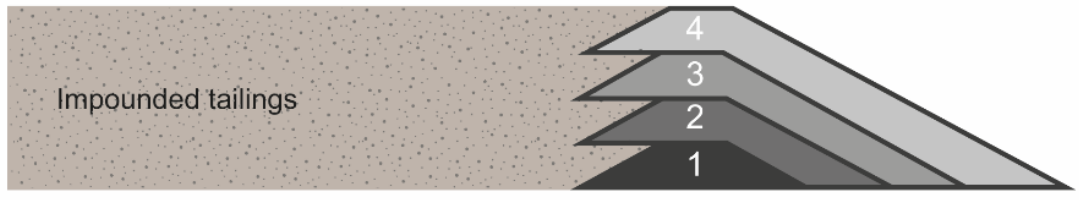

Centreline construction method 
The possible problems related to the above structures include damage to their physical or chemical stability due, for example, to slope failures or seepage. In the case of tailings dams sites, breaching is also a catastrophic type of failure. If any of the three types of tailings dams shown in Fig. 1, fail they can release both tailings and contaminated drainage downstream. The release of tailings downstream, which is likely to have catastrophic impacts can take place in different ways depending on the mode of failure and the type of structure involved. Figure 2 provides an overview of the main ways in which tailings dams can fail and provides an overview of what EO-based methods can monitor.

Tailings are deposited in the tailings pond as a slurry and contain a certain amount of water. If released downstream as a result of a dam failure, the tailings will generate a mudflow. At closed and abandoned sites, tailings have, in general, a much lower content of water and therefore, if the sites fail, the material released takes the form of an unsupported mass moving downward. At abandoned sites, the tailings may not be sealed or have any protection around them and the action of rainfall or runoff over the deposits can erode the material and mobilize tailings downstream.

Another typical release from tailings sites is contaminated drainage, a mix of water and pollutants, which constitutes one of the most serious environmental problems in the mining industry. The most common contaminated drainage is acid mine drainage (AMD), acidic water resulting from the exposure of sulphides in the tailings to oxygen and water causing the generation of sulphuric acid. Depending on the characteristics of the tailings though, alkaline contaminated drainage is also possible.

Effective monitoring of tailings storage facilities can result in early warnings of potential failures or the leaching of pollutants, which can subsequently minimize or eliminate the social, environmental, and economic losses they produce. Figure 3 shows, as an example, how the development of seepage from a tailings dam can lead to breaching. By detecting seepage soon after it occurs (e.g. at time $T_{1}$ in Fig. 3 ), the amount of damage can be minimized. However, if the seepage is detected later (e.g. at time $T_{2}$ in Fig. 3 ) the losses will be greater. If the seepage is not detected, the structure may fail catastrophically leading to a significant increase in losses. Table 1 summarises the results of monitoring and, depending on the level of detected alerts, from Level 1 (low) to Level 3 (high), the types of actions that could be taken.

Table 1: Examples of early actions that can be taken at tailings storage facilities as a result of effective monitoring

\begin{tabular}{|c|c|c|c|}
\hline Monitoring & \multicolumn{3}{|c|}{ Types of Actions } \\
\hline \multirow[t]{2}{*}{$\begin{array}{l}\text { Defect detected at } \\
\text { time T1 owing to } \\
\text { monitoring, see Fig. } 3\end{array}$} & Level 1 & & $\begin{array}{l}\text { Increase monitoring and surveillance activities taking more detailed and } \\
\text { focussed measurements in highlighted areas } \\
\text { Change mining operations (e.g. adjusting tailings deposition location) } \\
\text { Undertake minor repair works if needed }\end{array}$ \\
\hline & Level 2 & & $\begin{array}{l}\text { Stop mining production } \\
\text { Reassess stability with more detailed data } \\
\text { Preventative closure of water sources downstream to avoid contamination risk } \\
\text { Undertake repair works if needed }\end{array}$ \\
\hline $\begin{array}{l}\text { Defect detected at } \\
\text { time T2 owing to } \\
\text { monitoring, see Fig. } 3\end{array}$ & Level 3 & & $\begin{array}{l}\text { Activate emergency plans including: } \\
\text { Alert and evacuation of the population at risk } \\
\text { Closure/protection of main infrastructure }\end{array}$ \\
\hline
\end{tabular}




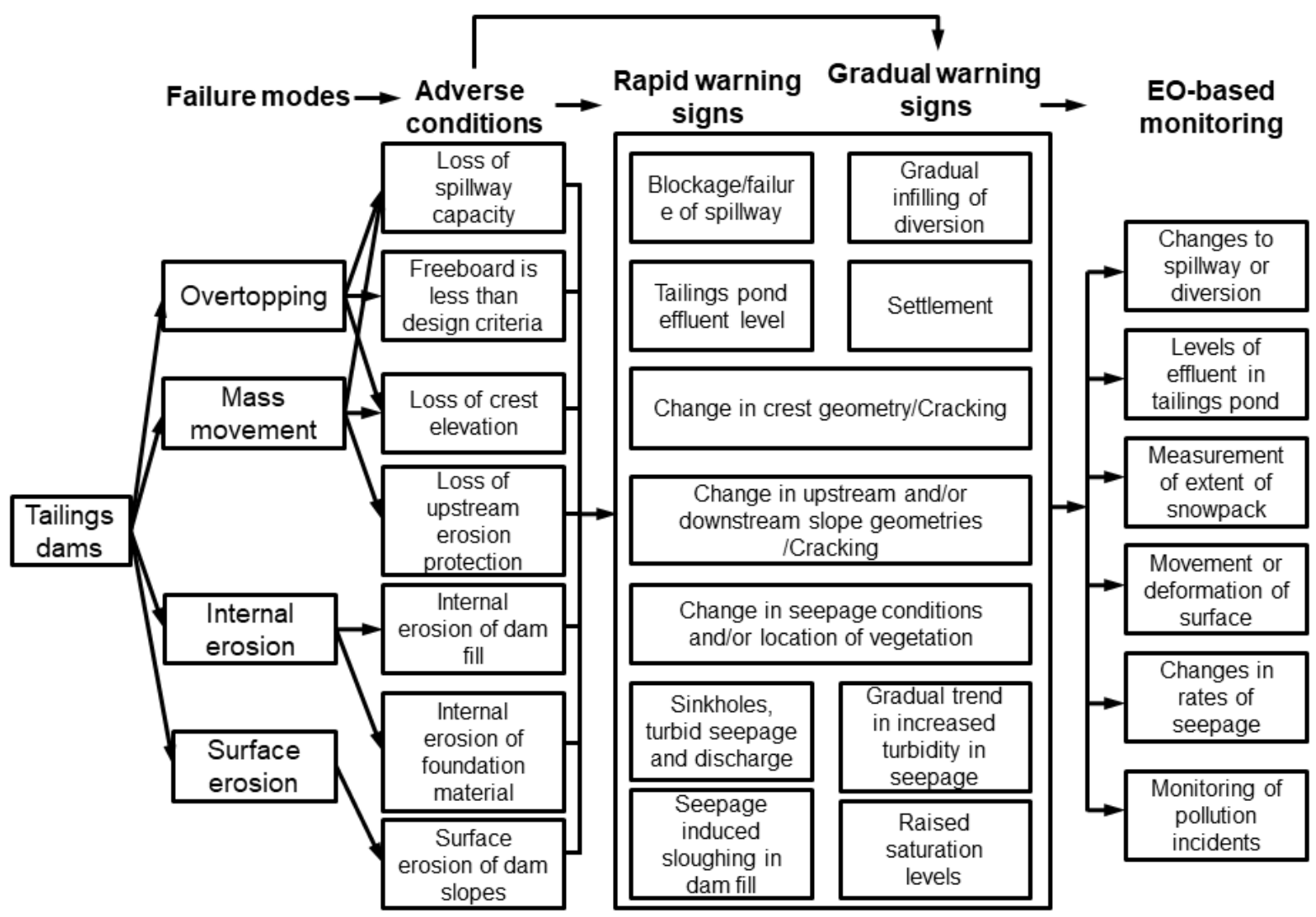

Figure 2. The main tailings dam failure modes, warning signs and what EO-based methods can monitor (Adapted from Martin and Davies 2000)

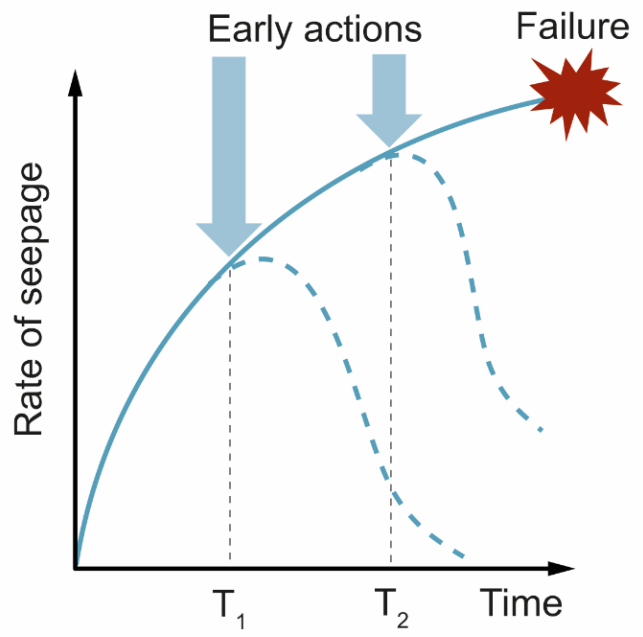

View 1

The effect of early actions on the rate of seepage as a result of early actions being undertaken at time $T_{1}$ and $T_{2}$

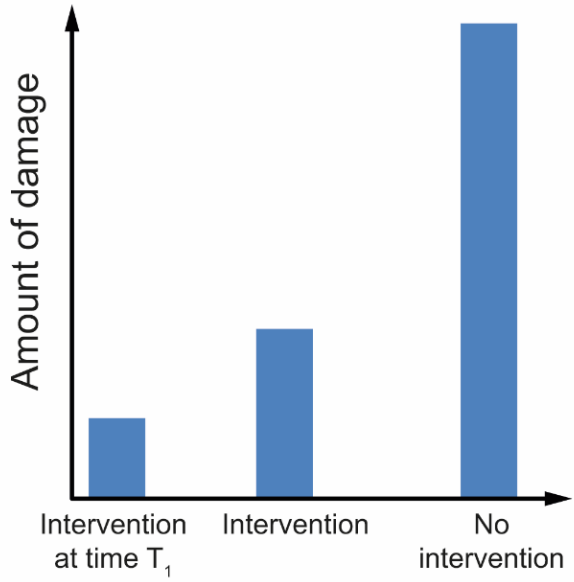

View 2

Relative amount of damage as a result of making interventions

Figure 3: The effect of early action as a result of effective monitoring in reducing the damage caused by tailings dams 


\section{State of the art remote sensing technology and how it can be used to monitor tailings dams}

Most of the recent tailings dam failures could have been prevented, either by improvements in their design or by better operational management (Bowker and Chambers 2017). However, as stated above, many regulatory bodies in low income countries do not have the resources to adequately monitor tailings dams and mining operations. Although it is not possible to determine the actual level of monitoring for tailings dams by mining companies worldwide, it appears that many of the large tailings dams are monitored using, at the minimum, regular visual inspections. In most cases, there is also some form of in-situ instrumentation (e.g. piezometers, drain flow meters; Lumbroso et al. 2019). However, the rate of failure of tailings dams owned by large mining companies has remained constant, or in some parts of the world increased in the past 20 years, despite there being no obvious barriers for these firms to use the best available monitoring techniques (Lumbroso et al. 2019).

There are also a very large number of small, unmonitored operating and non-operating tailings dams (Lumbroso et al. 2019). In the past 30 years, there has been an increased number of mines operating on low profit margins by less experienced and less financially stable miners. This poses a difficult challenge to significantly reducing tailings dam failures; hence, there is an acute need to monitor junior mining operations (Lumbroso et al. 2019). Recent work has shown that a low-cost tool, which uses EO-based information, could help improve the capacity of environmental regulators and non-governmental organisations (NGOs) to monitor tailings by improving their oversight of both large and small mines (Chetty 2013; Hui et al. 2015; Thomas et al. 2019).

EO-based data provides a means by which monitoring of tailings dams could be improved. EO-based monitoring methods are unlikely, in the foreseeable future, to make in situ monitoring methods redundant; however, they do provide regulators and civil society organisations with an eye in the sky via which the risks posed by tailings dams can be prioritised and, in some cases, predicted in advance, allowing them to be mitigated. Table 2 provides an overview of the EO-based data that has been used in DAMSAT, what aspects of tailings dams it can be used to monitor, together with a summary of its advantages and disadvantages. 


\begin{tabular}{|c|c|c|c|}
\hline EO technology & Data provided & $\begin{array}{l}\text { Use of EO-technology with } \\
\text { tailings dams }\end{array}$ & $\begin{array}{l}\text { Advantages and disadvantages of } \\
\text { the EO technology }\end{array}$ \\
\hline $\begin{array}{l}\text { Interferometric } \\
\text { Synthetic } \\
\text { Aperture Radar } \\
\text { (InSAR) }\end{array}$ & $\begin{array}{l}\text { Relative displacement of the dam or structure } \\
\text { to an accuracy of a few mm. } \\
\text { Assessment of water in the pond. } \\
\text { Digital terrain model (DTM) creation }-0.5 \mathrm{~m} \\
\text { horizontal resolution DTMs with } 10 \mathrm{~cm} \\
\text { vertical resolution and absolute accuracies } \\
\text { approaching } 3.5 \mathrm{~m} \text { with no ground control. }\end{array}$ & $\begin{array}{l}\text { Monitoring of abnormal deformation of the } \\
\text { structure. } \\
\text { Monitoring of movement of the natural } \\
\text { ground in key areas of risk, such as at the } \\
\text { dam abutments or the reservoir rim. } \\
\text { Assessment of tailings and water areas in } \\
\text { the ponds. }\end{array}$ & $\begin{array}{l}\text { Advantages } \\
\text { Provides a method for a relatively limited staff } \\
\text { to remotely monitor thousands of points on a } \\
\text { tailings dam to assess if there have been } \\
\text { significant deformations. Allows monitoring of } \\
\text { abandoned, uninstrumented tailings dams in } \\
\text { remote locations to be monitored. } \\
\text { Disadvantages } \\
\text { Freely available InSAR has limited accuracy, } \\
\text { making it more challenging to depict } \\
\text { "abnormal" displacements. } \\
\text { More accurate, commercially available InSAR } \\
\text { information is relatively expensive. }\end{array}$ \\
\hline $\begin{array}{l}\text { Optical-based } \\
\text { satellite data }\end{array}$ & $\begin{array}{l}\text { Features identification and ortho-mapping, } \\
\text { with increasingly short return periods } \\
\text { combined with high resolution of up to } 40 \mathrm{~cm} \\
\text { from low earth orbit; optical data provides } \\
\text { synoptic, accurate and fresh context mapping } \\
\text { of an entire site at very low cost per square } \\
\mathrm{km} \text {, generally from a single shot. } \\
\text { Spectral classification: contaminated land } \\
\text { indicators such as vegetation die back and } \\
\text { water discolouration can be determined from } \\
\text { these. } \\
\text { Change detection: high, almost daily revisit } \\
\text { of sites affords opportunity to monitor } \\
\text { landscape changes for detecting and } \\
\text { mapping rapidly evolving processes and } \\
\text { activities. }\end{array}$ & $\begin{array}{l}\text { Leaching of tailings from the structure } \\
\text { indicated by declining vegetation health or } \\
\text { increasing iron oxide traces. Changes in } \\
\text { seepage rates that could indicate internal } \\
\text { erosion issues in the dam body. Measures } \\
\text { width of the beach formed as tailings are } \\
\text { deposited, which keeps the supernatant } \\
\text { pond away from the dam and the phreatic } \\
\text { surface low, thus reducing the risk of } \\
\text { failure. Slope failure detection, especially } \\
\text { relevant for closed sites, using a } \\
\text { combination of parameters (e.g. soil } \\
\text { moisture, muddiness, surface features, } \\
\text { slope change). }\end{array}$ & $\begin{array}{l}\text { Advantages } \\
\text { Thousands of tailings dams in remote } \\
\text { locations can be monitored effectively by a } \\
\text { small number of people. } \\
\text { Disadvantages } \\
\text { Cloud cover can hamper and limit image } \\
\text { availability. The temporal resolution of days } \\
\text { rather than a few hours may also be a } \\
\text { constraint for some users. When used to } \\
\text { assess leaching from tailings dam, the size of } \\
\text { the anomaly needs to bigger than the pixel } \\
\text { resolution of the EO data }\end{array}$ \\
\hline
\end{tabular}




\section{EO technology}

\section{Global}

Navigation

Satellite System

(GNSS)

Global weather forecasting

models

\section{Data provided}

GNSS can be used to autonomously compute three-dimensional motion vectors of a number of points using standard in-situ located GNSS receivers to an accuracy of a few millimetres.
Use of EO-technology with

tailings dams

Monitoring of abnormal deformation of key specific points of the structure in real time

(requires a base station to be installed)
Forecasts of climate variables such as rainfal and temperature from, e.g. the European Centre for Medium-range Weather Forecasting (ECMWF) or the Global Forecast System (GFS) produced by the National Centers for Environmental Prediction. The GFS forecasts are available at $\approx 50 \mathrm{~km}$ or 0.5 degree resolution. The ECMWF forecast are available at $\approx 18 \mathrm{~km}$ or 0.2 degree of resolution.
Forecasts of runoff that can be used to assess the probability of overtopping, or a potential dangerous increase in the moisture content of the dam body that could affect stability.
Advantages and disadvantages of

the EO technology

\section{Advantages}

GNSS has a high degree of accuracy, i.e. a few $\mathrm{mm}$, and provides real-time displacement measurements and changes in levels.

\section{Disadvantages}

Expensive to purchase and install. Capital and installation costs can range between $\approx$ U.S. $\$ 60,000$ and $\$ 120,000$ per installation.

Equipment needs to be installed in a secure location because it can be easily vandalised. The GNSS equipment can only be monitored where it is installed and requires a $\mathrm{Wi}-\mathrm{Fi}$ connection and continuous power supply.

\section{Advantages}

Provides lead times between 10 and 15 days of potential extreme hydrological events that could affect a tailings dam. Some weather forecasts are probabilistic, which allows degree of uncertainty to be assessed

\section{Disadvantages}

The results of rainfall-runoff models driven by weather models have a high degree of uncertainty, especially in areas where no data is available to calibrate them. More accurate weather forecasts (such as those provided by ECMWF) are more expensive than those provided for free by the GFS. Depending on the variables required, the cost can be U.S. $\$ 10,000$ to $\$ 50,000$ per annum. Ideally, observed flows and rainfall data are used to calibrate the hydrological model. 


\section{DAMSAT functionality and modules}

\subsection{Introduction}

The DAMSAT system is a project being piloted in Peru. From the commencement of the project, key Peruvian stakeholders, including the Ministry of the Environment, Ministry of Energy and Mines, the Agency for Environmental Protection and Enforcement, the National Water Authority, and others were engaged with to elicit their user requirements related to the monitoring of tailings storage facilities, as well as helping to design the different modules of the system. Many of these organisations reported that they have limited resources and are not able to visit tailings dam sites frequently (Lumbroso et al. 2019). The stakeholders' requirements for an EO-based monitoring system for tailings dams are summarised below:

- Inform assessments of tailings dam safety and performance in accordance with design criteria and objectives

- Assist in identifying and forecasting when there is a high probability of failure

- Forecast and identify potential pollution incidents

- Effectively communicate the degree of risk posed by tailings dams so that appropriate actions are implemented at national and local government levels and also at-risk communities

The system contains a number of modules, which together with their sources of information and functionality, are summarised in Table 3.

\section{Table 3: DAMSAT modules including sources of information and functions}

\begin{tabular}{|c|c|c|}
\hline Module & Sources of information & Functionality \\
\hline Visualisation & $\begin{array}{l}\text { Sentinel } 2 \text { satellite data with } 10 \text { m resolution } \\
\text { High resolution satellites available in the area }\end{array}$ & $\begin{array}{l}\text { Allows visual inspections of particular sites. } \\
\text { Compares current image with historical images to } \\
\text { assist users detect interesting changes on site. }\end{array}$ \\
\hline $\begin{array}{l}\text { Movement } \\
\text { detection }\end{array}$ & $\begin{array}{l}\text { InSAR Sentinel-1 satellite data } \\
\text { InSAR high resolution satellites available in the } \\
\text { area } \\
\text { GNSS in-situ sensors }\end{array}$ & $\begin{array}{l}\text { Provides an indication of displacements at the } \\
\text { structure and in nearby points. }\end{array}$ \\
\hline $\begin{array}{l}\text { Leaching } \\
\text { detection }\end{array}$ & $\begin{array}{l}\text { Sentinel } 2 \text {, with a } 10 \mathrm{~m} \text { resolution } \\
\text { High resolution satellites available in the area }\end{array}$ & $\begin{array}{l}\text { Analysing sequences of optical data for signs of } \\
\text { iron oxide or vegetation health variations which } \\
\text { could indicate locations of potential pollution } \\
\text { events. }\end{array}$ \\
\hline $\begin{array}{l}\text { Hydro- } \\
\text { meteorological } \\
\text { forecasting }\end{array}$ & $\begin{array}{l}\text { National Oceanic and Atmospheric } \\
\text { Administration (NOAA) global forecast system } \\
\text { ECMWF weather forecast }\end{array}$ & $\begin{array}{l}\text { Provides forecasts up to } 10 \text { days into the future of } \\
\text { (1) precipitation (2) runoff into the reservoir (3) } \\
\text { water level change at the pond. }\end{array}$ \\
\hline $\begin{array}{l}\text { Emergency } \\
\text { planning }\end{array}$ & $\begin{array}{l}\text { Output from dam break and inundation models } \\
\text { Characteristics of buildings, people, and road } \\
\text { networks downstream of the dam, as well as } \\
\text { the output from inundation model }\end{array}$ & $\begin{array}{l}\text { The emergency management module uses dam } \\
\text { break modelling, inundation modelling and the } \\
\text { agent-based Life Safety Model to estimate the risk } \\
\text { to people, evacuation times, and emergency } \\
\text { management strategies (e.g. the location of safe } \\
\text { havens, improved early warnings), which could } \\
\text { reduce risks to people. }\end{array}$ \\
\hline
\end{tabular}


The system runs on a secure cloud-based platform and brings together data from a number of EO data sources, weather forecasts, and on-the-ground sensors. An internet browser based interface allows users to view the outputs of the modules and update operational parameters such as alert thresholds. Figure 4 shows the data flows, processes, objects and stores for the EO-based tools and modules included within DAMSAT. The sections below provide summaries of the EO methods underpinning each of the different DAMSAT modules.
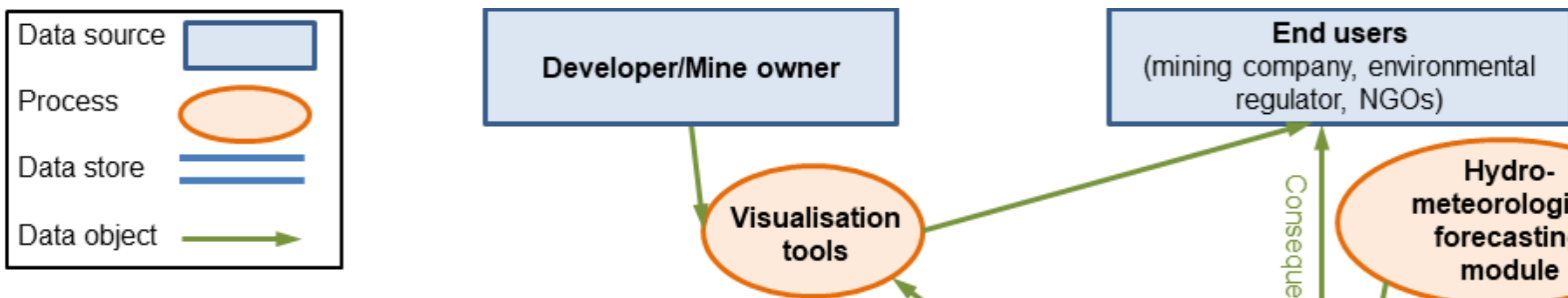
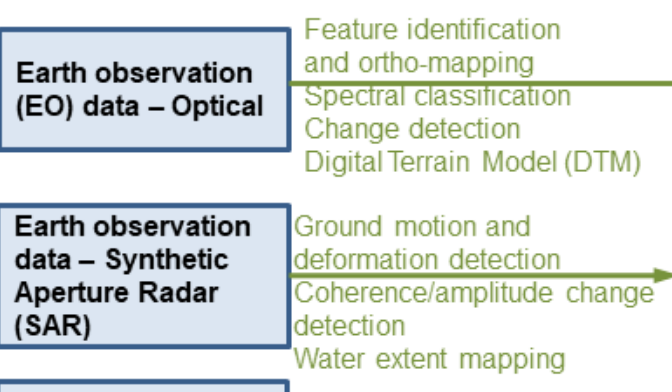

Earth observation
data - Synthetic
Aperture Radar
(SAR)

Global Navigation Satellite Systems (GNSS)

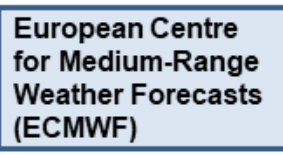

US National Weather Service's Global Weather Forecast System (GFS)
Real time motion detection

Short-term (i.e. up to 15 day at a $9 \mathrm{~km} \times 9 \mathrm{~km}$ grid resolution

\section{Short-term} weather forecasts at a $16 \mathrm{~km} \times 16 \mathrm{~km}$ grid resolution lead times) weather forecasts. meteorological forecasting module

Figure 4: An overview of the data flows, processes, objects, stores and modules included within DAMSAT

\subsection{Monitoring of Surface Movements using Space-borne Synthetic Aperture Radar Interferometry (InSAR) data}

Space-borne Synthetic Aperture Radar Interferometry (InSAR) is increasingly used to monitor wide-area to local scale ground motions. InSAR is non-intrusive and does not require any ground installations. The shorter the revisit time of the satellite, the more accurate the analysis of the temporal evolution of the deformation of a structure is likely to be. The repeat cycle of satellites with InSAR is sufficient to allow the changes in ground movements of tailings dams to be monitored almost daily at most mining locations (e.g. Sentinel-1A has a revisit time of 12 days; Tomás et al. 2014). 
InSAR data is freely available globally from a number of sources (e.g. Sentinel-1) and has been used to measure deformations in buildings and opencast mines for over a decade (Herrera et al. 2007).

Commercially available InSAR, such as COSMO-SkyMed, provides more accurate measurements of surface deformation (e.g. to a few millimetres); however, such sources can be costly. The system has been designed so that it provides the user with ability to use a range of InSAR information sources. The rate of change of the deformation of a tailings dam over time, based on InSAR data, can be used to help to predict if, and in which location, the structure has the highest probability of failing. In addition to ground movements, InSAR can, in some cases, offer the ability to remotely monitor the extent of larger tailings pond water levels.

\subsection{Monitoring of Surface Movements using Global Navigation Satellite System (GNSS) Technology}

Global Navigation Satellite System (GNSS) technology provides real-time, highly accurate measurements of surface deformations in all weather conditions. GNSS technology has been used to measure deformations of dams in China, the USA, and Spain (Scaioni et al. 2018; Xiao et al. 2019). DAMSAT has the ability to integrate readings from GNSS. GNSS-based solutions require a base station to be installed, as well as monitoring antenna and support boxes on the structure at the locations where information on movements are required. Typical costs of GNSS equipment and installation are between U.S. $\$ 60,000$ and $\$ 120,000$ (Lumbroso et al. 2019). GNSS equipment only provides real time measurements of deformations at the points on the dam where ground stations are located, with data being collected every minute, or less if required.

\subsection{Detection of leaching and pollution}

The use of spectral data and remote sensing for detecting minerals and analysing mining impact is well documented. Alexander et al. (1973) described the use of ERTS-1 (later called Landsat) multispectral data to evaluate the damage caused by surface mining. The contamination caused by leaching from tailings dam leakage can be detected using EO data by using the health levels of the vegetation downstream of the dam or by monitoring the presence of iron oxide in the environment. The method used in DAMSAT detects anomalies based on changes in the normalised difference vegetation index (NDVI) or in the soil's iron oxide content.

The use of changes in EO-based NDVI values has been used to detect pollution from mining operations (Alonzo et al., 2016; Hejmanowska et al. 2016; Sonwalka et al. 2010). Remote sensing derived data sets such, as NDVI, indicate the greenness of the vegetation. A significant drop in the vegetation's NDVI downstream of a tailings dam can be observed, compared to an average year.

The Sentinel-2 satellite provides information on soil attributes including levels of iron oxide, which has been shown to have a good correlation with potentially toxic elements being present (Van der Werff and Van der Meer 2015; Gholizadeh et al 2018). Hence, changes in iron oxide concentrations downstream of a tailings dam can also indicate that potentially toxic substances are seeping through the dam.

The change detection algorithm is based on a comparison of the image for the selected date with at most three co-registered previous images, where all images satisfy a cloud condition criterion (i.e. less than $75 \%$ of the image is covered by clouds). For NDVI, there is the additional criterion of the maximum time span between the analysed and comparison images of three months. This is to prevent change detection being 
triggered by seasonal changes in vegetal cover. The reason for using three comparison images rather than just one is to reduce falsely detecting pollution incidents due to ground or atmospheric changes similar to that of the target species.

For all images, an intensity corresponding to the targeted vegetation species is first calculated. For vegetation, this is:

$N D V I=\frac{(N I R-R E D)}{(N I R+R E D)}$

where: NIR is the reflectance in the near infrared band (Band 08 of Sentinel-2) and RED is the reflectance in the red band (Band 04).

For iron oxide, the respective intensity of the correlation coefficient between the observed spectrum and spectra of the iron oxide signatures reported in the literature (Seifi et al. 2019), as well as those sampled from the Brumadinho tailings dam failure, is used. For all pixels not covered by clouds, the difference in the parameter value between the selected image and each of the comparison images is computed to obtain a scalar (grey scale) difference image (one for each comparison image). The next step is to run the principal component analysis on this difference image to extract the pixels where the probability of change exceeds the pre-determined threshold. (For examples of using this method for unsupervised change detection in satellite images, see Celik 2009.) If the probability for the same pixel exceeds the threshold in at least two comparisons (or one if the pixel is covered by clouds), then the algorithm raises a warning with respect to where changes in NDVI or in the presence of iron oxide has occurred. Changes in these variables are likely to be "non-natural" if they have an artificial shape and are local in scale.

\subsection{Hydro-meteorological forecasting}

Short term weather forecasts from the European Centre for Medium Range Weather Forecast (ECMWF) and The National Oceanic and Atmospheric Administration (NOAA) Global Forecasting System (GFS) are coupled to hydrological models, which allow inflows towards tailing dams to be estimated. Existing drainage systems to divert runoff from the catchment around the dams are also considered in the estimates. The inflows and rainfall are also used to estimate the likely increase of water levels at the pond. Estimations are quantified with a lead time of up to 10 days. The forecast inflows are updated automatically every six hours, together with the forecast rainfall and water levels in the tailings pond. These probabilistic forecast are displayed as shown in Fig. 5. 


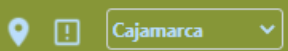

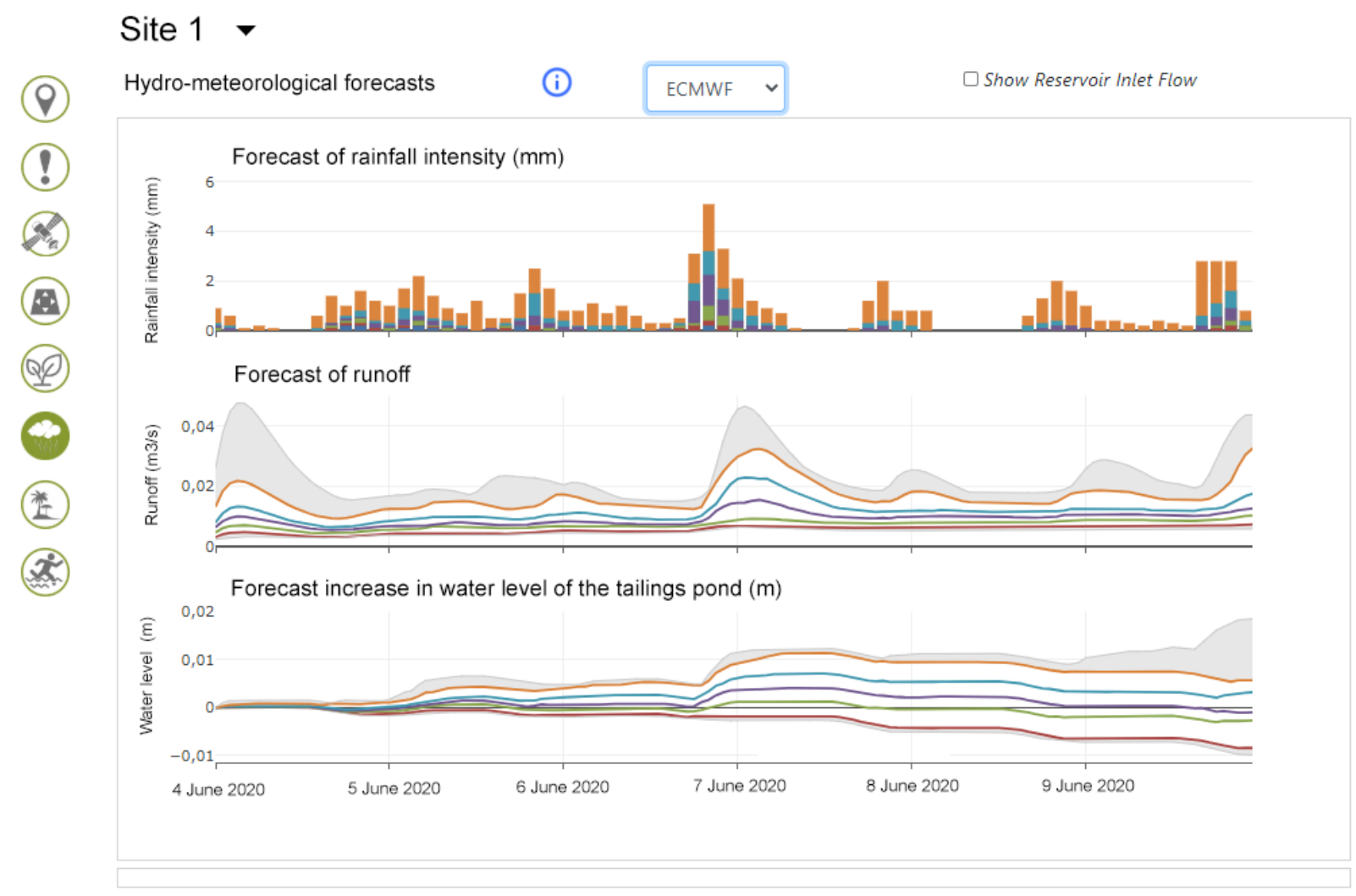

Figure 5: An example of the probabilistic forecasts of rainfall intensity, runoff, and water levels for a tailings dam site in Peru

\subsection{Emergency planning}

Agent-based models, such as the life safety model (LSM) used in DAMSAT, provide information to support emergency planning. The LSM models the behaviour of people, cars, and buildings downstream of a tailings dam and their interaction with the mud flow following a breach. The LSM allows the following to be estimated:

- The number of people likely to die or be injured as a result of a tailings dam failure

- The number of buildings that are likely to be destroyed

- The time required for people to evacuate the area at risk on foot and in vehicles

- The effect of measures such as improving early warnings and evacuation routes on reducing the risk to people (Di Mauro and Lumbroso 2008; Lumbroso and Davison 2018)

The LSM has been used to analyse the risk to people from dam failures and floods worldwide (Johnstone 2012; Lumbroso and Davison 2018). The model has been validated using data from the 1959 Malpasset Dam disaster in France and used for emergency planning for flood events worldwide (Lumbroso and Tagg 2011; Lumbroso et al. 2011). The vulnerability functions for people and buildings in the LSM were originally 
developed based on the characteristics of floodwater, but these can be modified to consider that tailings dam failures produce a mudflow which, unlike floodwater, is non-Newtonian in nature. The LSM was used to model the Brumadinho tailings dam failure in Brazil that occurred in January 2019 (Lumbroso et al. 2020). The LSM was run for a number of scenarios and estimated that between 216 and 345 died. The actual number of fatalities was about 300 people (Keaveny 2019; Mining Journal 2020). The LSM allows the effects of improved warnings on loss of life and evacuation times to be assessed. Research on the Brumadinho case study found that even if a warning had been provided just as the dam failed, the number of fatalities could have been significantly reduced (Lumbroso et al. 2020).

The LSM uses the water or mudflow depths and flow velocities from a two dimensional mud and flow inundation model as input. To determine the mud flow being released during the failure, a dam breach model called EMBREA-MUD has been specifically developed for tailings dams (see Petkovšek et al. 2020 for more details). EMBREA-MUD is based on a predictive dam breach model developed over a number of years (see Mohamed et al. 2002; Morris 2011). This model simultaneously computes the outflow of water and tailings from a tailings dam and the corresponding growth of the opening. Tailings outflows are represented by a separate non-Newtonian viscous layer, as well as a water layer. The tailings dam model was verified using empirical data from laboratory tests, as well as data from the Mount Polley tailings dam failure in Canada in 2015 and the Merriespruit tailings dam disaster that occurred in South Africa in 1994 (Petkovšek et al. 2020).

\section{Application of DAMSAT in Peru}

\subsection{Introduction}

The DAMSAT system is currently being piloted in the Cajamarca and Pasco regions of Peru to help infrastructure and environmental regulators improve their monitoring of both active and inactive tailings dams. Cajamarca is home to a number of large gold and copper mines, while Pasco is a region with a long mining tradition. Peru has hundreds of active tailings dams and thousands of abandoned tailing deposits storing chemicals and waste that have the potential to pollute the downstream environment.

Over the past decade, there have been a number of tailings dam incidents in Peru. Most recently, in July 2019, it was reported that a spill from a tailings dam at the Cobriza copper mine led to the Mantaro River being severely polluted with cyanide up to $375 \mathrm{~km}$ downstream from the dam (Mining Journal 2019; Petley 2019) and in 2010 a tailings dam failure at Huancavelica polluted some $110 \mathrm{~km}$ of the Escalera and Opamayo Rivers (Minerals Policy Institute 2014).

The impacts of mining on water quality and environmental health originate primarily from AMD and the escape of ancillary products. In July 2008, Peru declared a state of emergency at a mine near Lima over concerns that a tailings dam, weakened by seismic activity and subterranean water filtration, could release arsenic, lead, and cadmium into the main water supply for the capital (Beddington and Williams 2008). It has been estimated that over 13 billion $\mathrm{m}^{3}$ of effluent from mining operations are released annually into Peru's water environment (Beddington and Williams 2008). This section provides details of how some of the modules have been implemented in Peru. The names and exact locations of some of the examples have not been provided owing to reasons of confidentiality. 


\subsection{Monitoring Tailings Dam Displacements using Sentinel-1 InSAR Data and GNSS Monitoring Equipment}

The use of Sentinel-1 InSAR data has been piloted on seven large (i.e. higher than $15 \mathrm{~m}$ ), tailings dams in Peru. Figure 6 shows an example of Sentinel-1 InSAR displacement results for one of these dams for a 15 month period between Aug. 2018 and Oct. 2019.

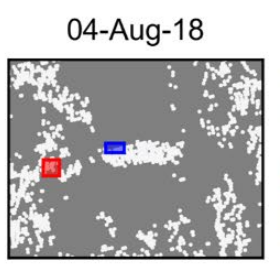

13-Apr-19

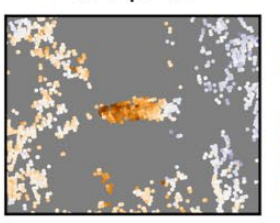

21-Sep-18

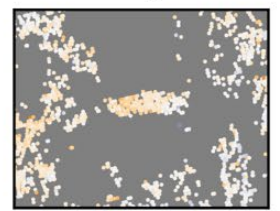

31-May-19

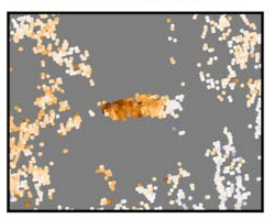

08-Nov-18

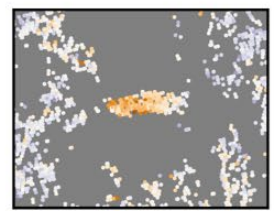

06-Jul-19

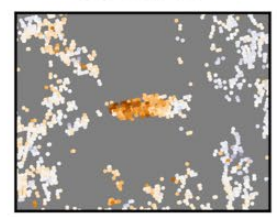

14-Dec-18

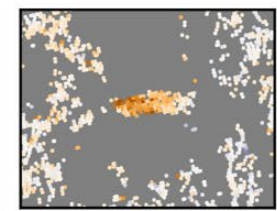

23-Aug-19

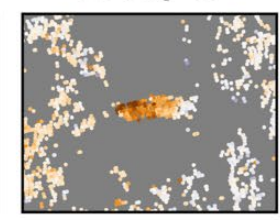

31-Jan-19

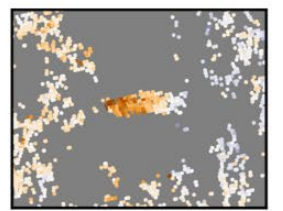

16-Sep-19

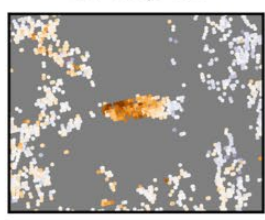

08-Mar-19

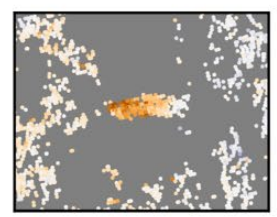

10-Oct-19
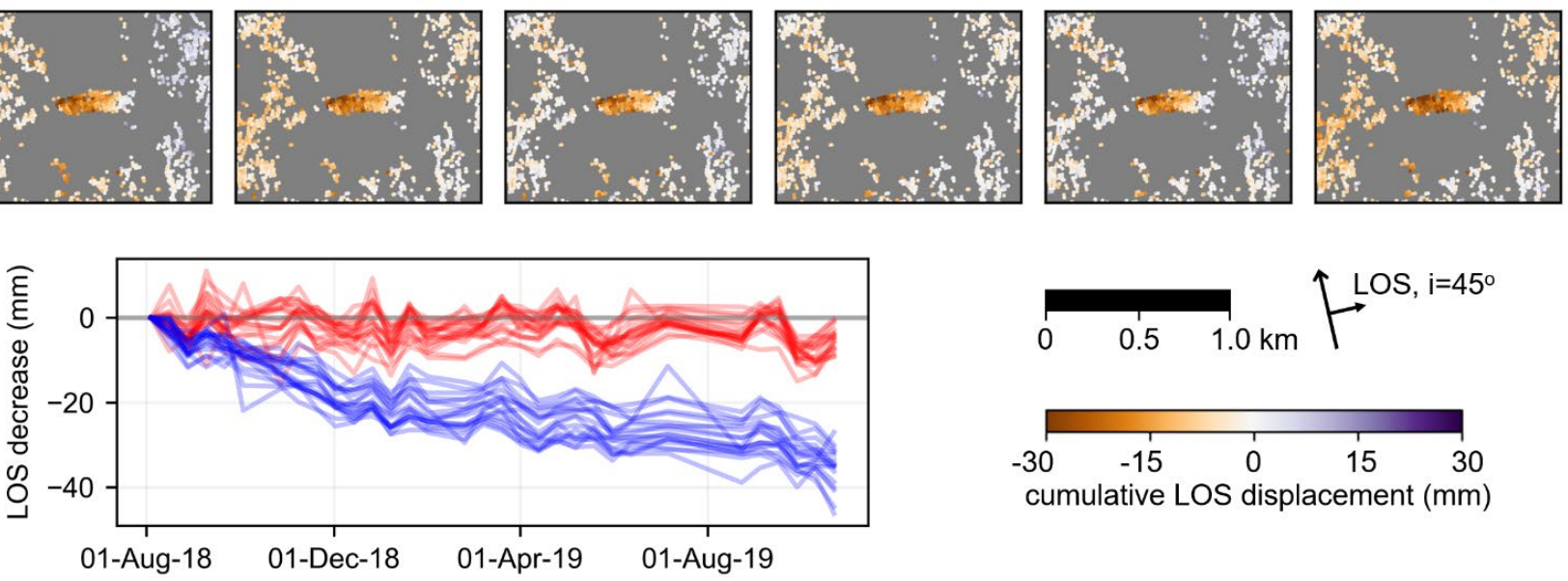

Figure 6: Example of Sentinel-1 InSAR displacement results for a tailings dam in Peru. Top: Maps of cumulative line-of-sight (LOS) displacement of a dam and the surroundings between Aug. 2018 and Oct. 2019. Bottom: Displacement time series graphs for the points within the red and green boxes shown on the top left map. Negative LOS decrease corresponds to movement in the direction away from the satellite. This figure contains modified Copernicus Sentinel data

The InSAR results are displayed in several ways on the web-based system. The main method of display is a map, making it easy for users to visualise areas of the structure that may be problematic with regards to possible abnormal deformations. A "hotspotter" summarises the information from all the points, which helps to identify these areas. The increase in the line of sight (LOS) displacement is also plotted against time (see Fig. 6). Work carried out on the failure of the tailings dam at the Cadia gold mine in New South Wales, Australia has indicated that using InSAR satellite data together with the inverse of velocity $\operatorname{method}^{1}$, the timing of the failure could have been predicted almost one month in advance (Carlà et al 2019; Tre-Altimira 2018).

\footnotetext{
${ }^{1}$ The inverse velocity method is used to calculate the rate of deformation of the slope of the dam (velocity) and to plot the inverse of the rate of deformation against time (i.e. the inverse velocity against time). As the velocity or rate of deformation increases, the inverse will tend towards zero, which is when failure occurs. For more details of this method, see Carlà et al. 2017.
} 
In addition, GNSS monitoring stations have been installed on a tailings dams in Peru (Fig. 7). The GNSS monitoring stations provide real-time information on tailings dam movements with a high degree of accuracy (e.g. a few millimetres); however, they are relatively expensive (see Table 2). The monitoring equipment comprises a SUMMIT box, which is a computer running proprietary software, combined with three GPS satellite signal monitoring units, called GNSS monitoring and reference units. The SUMMIT boxes were installed in buildings on or near the site to protect them from the weather. They require a continuous supply of power, together with a connection to the internet to allow remote user monitoring. On each site, one of the GNSS monitoring units was designated as the reference unit, and installed at a location that does not move relative to the dam. The other two GNSS units, referred to as the GNSS monitoring units, were installed at locations where movements are anticipated. The GNSS antennas were mounted in a way that provides them with a sufficiently clear view of the surrounding sky (Fig. 8).

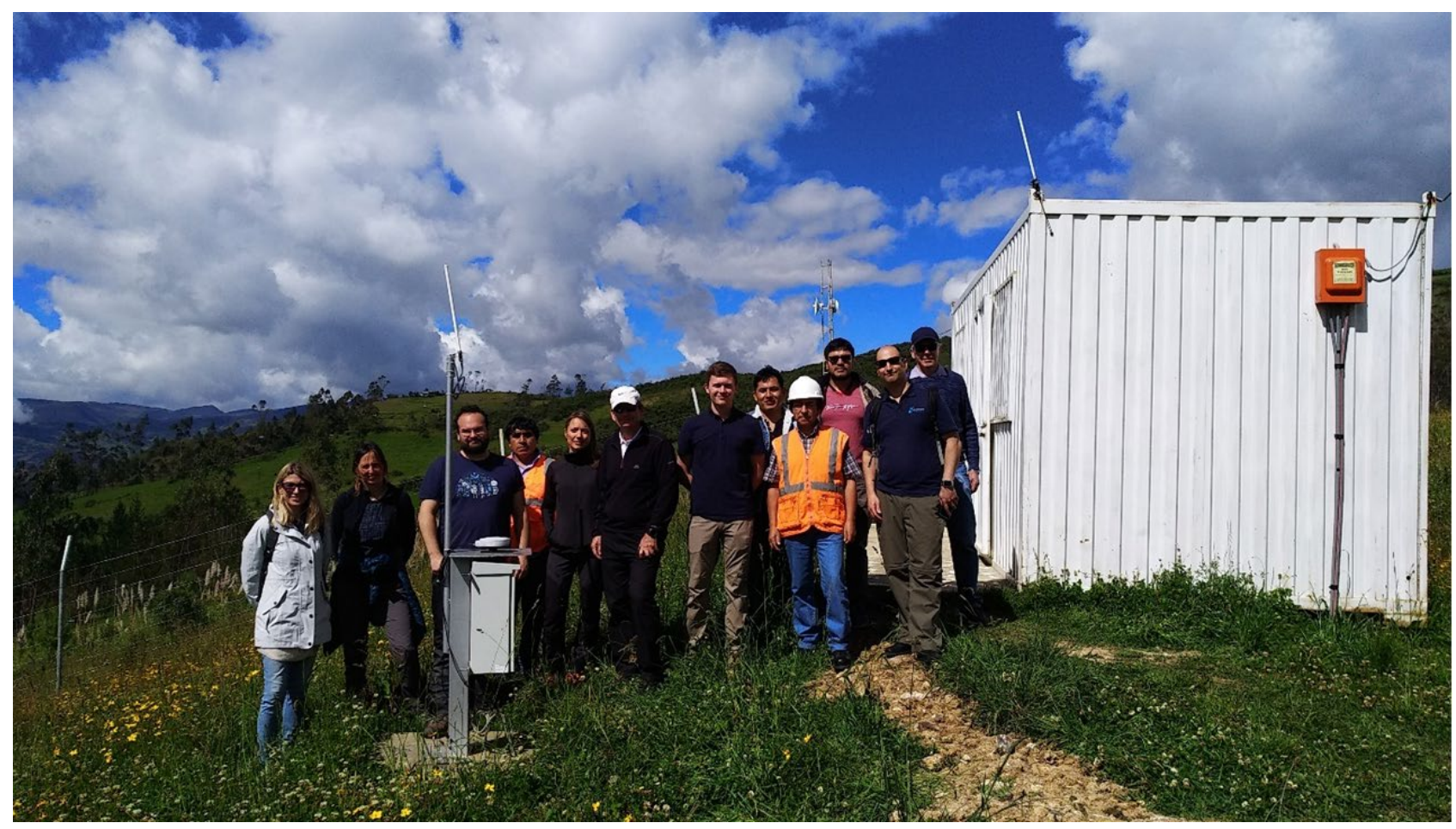

Figure 7: GNSS monitoring station installed (at the front) and building with the SUMMIT box on the right on a tailings deposit in Peru 


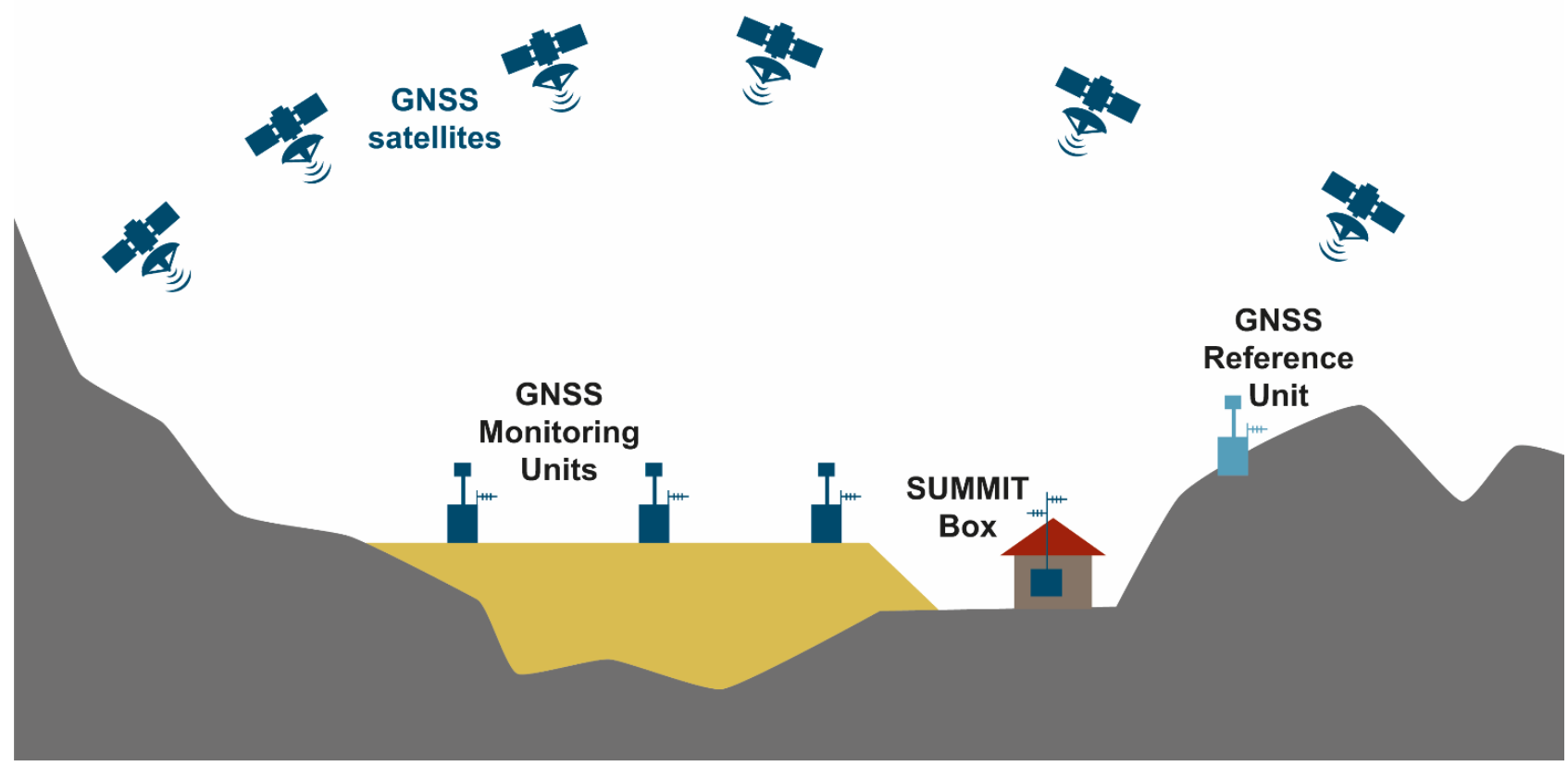

Figure 8: Schematic diagram showing the setup of the GNSS monitoring stations and SUMMIT box

A module has been included in the system that generates warnings when certain deformation or movement thresholds are reached. The users can manage those alerts, change their status, and make comments. The system is flexible so that it can be modified for different structures. An example of the web-based alert system is shown in Fig. 9.

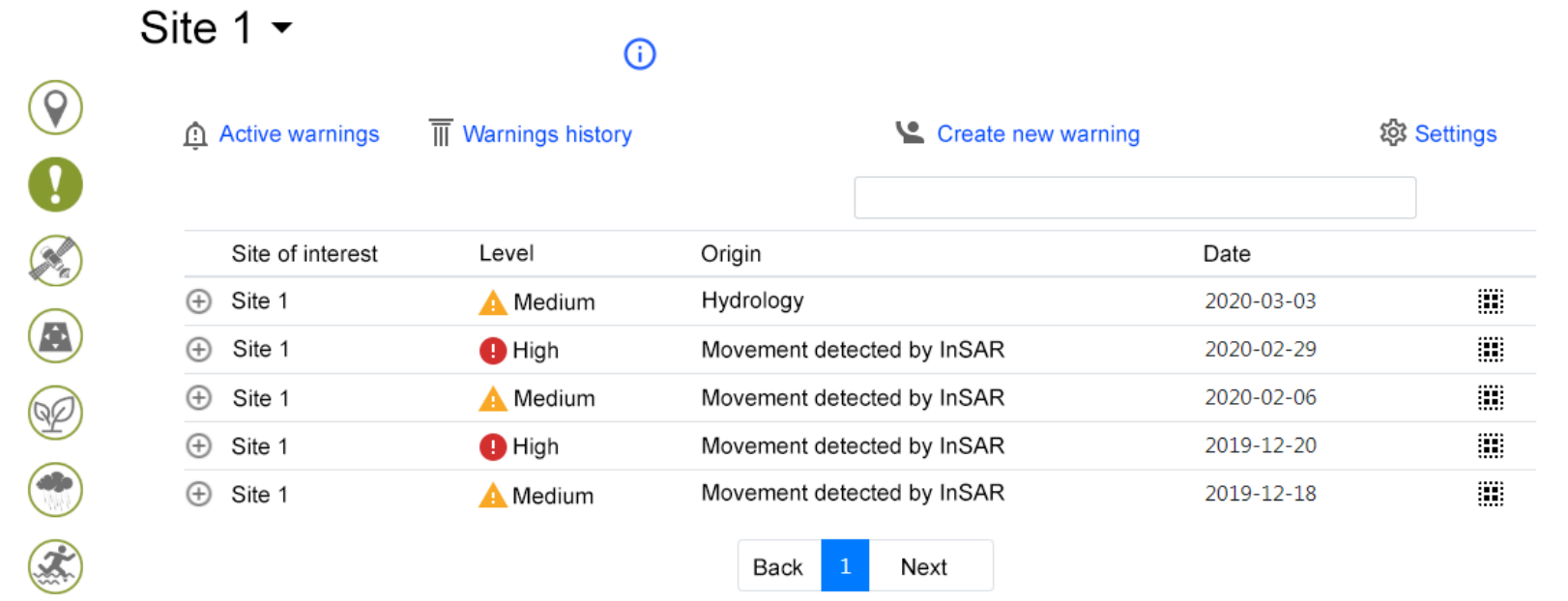

Figure 9: Example of the web-based warning system alerting users to possible issues 


\subsection{Assessment of leaching using optical Imagery}

The leaching module uses optical imagery. The two methods by which pollution is detected have been discussed above: direct pollution detection using iron oxide as a proxy for leaching, and indirect pollution detection using NDVI to monitor the changes to the health of the vegetation adjacent and downstream of a tailings dam. The leaching module uses optical data from Sentinel-2 over seven bands and has been applied to two tailings dams in Peru. An example of its application to a tailings dam in Peru is shown (Fig. 10).

\subsection{Emergency planning for tailings dams in Peru}

The Peruvian stakeholders are interested in the risks posed by tailings dams, both in terms of loss of life and other damage, so that their limited resources can be targeted at the structures that pose the greatest risk. The LSM has been used on a number of tailings dam sites in Peru. The mudflow from a breach of the dam is estimated using EMBREA-MUD and the resulting mud hydrograph is used to drive a two dimensional model of the mudflow, the results of which are used in the LSM. Data on the number of people, buildings, and the road network downstream of the dam are taken from openly available data or digitised from maps. The LSM model is run for several scenarios, such as:

- No warning

- Siren based warning at the time of failure

- Siren based warning 5 minutes before failure

- Siren based warning 15 minutes before failure

The uncertainty in the response of people to hearing the warning siren is assessed by simulating delay times in the response of people to the warning of 5 and 15 minutes. The results for a specific tailings dam in the Pasco Region of Peru are summarised in Table 4, showing that the estimated number of fatalities (around $84 \%$ of those at risk) are very high when a warning is not issued. The LSM results show that a warning issued 10 minutes before the failure can significant reduce the risk to people, if they know how to respond.

The LSM has been used to assess the risk to people at a number of tailings dams in Peru because it allows regulators to quantify the risk they pose to people and to use the information to develop emergency evacuation strategies, such as informing those at risk to escape to local safe zones above the mudflow inundation zone. 


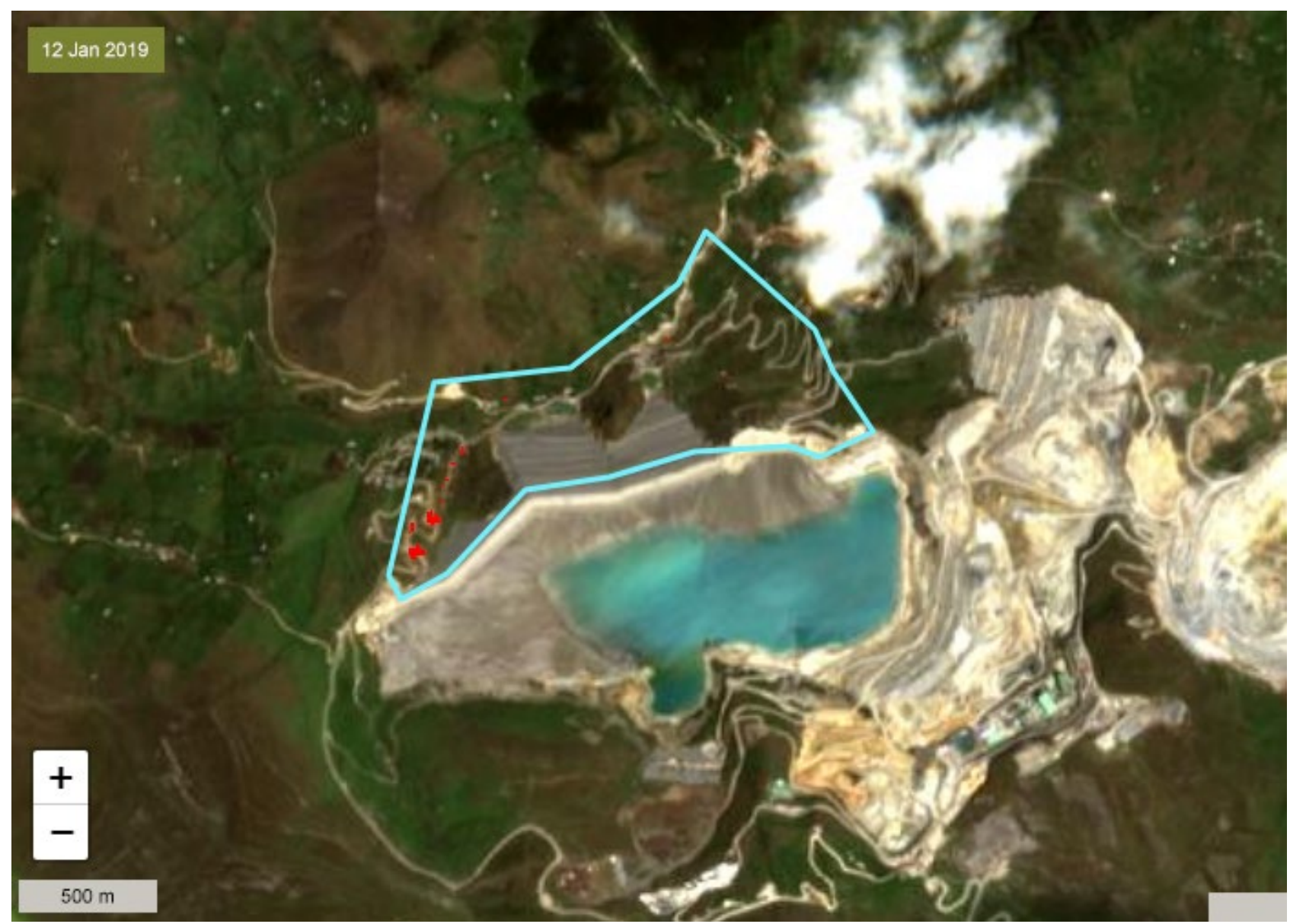

Figure 10: Example of change in NDVI for a tailings dam in Peru on 12 Jan. 2019, based on a comparison between the first clear day post-incident image and three pre-incident images. The spill occurred on 16 December 2018 from the left side of the dam.

Table 4: The potential number of fatalities caused by the failure of a dam in the Pasco Region for a range of warning and response times

\begin{tabular}{|c|c|c|}
\hline \multirow[b]{2}{*}{ Time the warning was issued } & \multicolumn{2}{|c|}{ Number of fatalities } \\
\hline & $\begin{array}{l}\text { Five minutes before } \\
\text { people respond }\end{array}$ & $\begin{array}{l}15 \text { minutes before } \\
\text { people respond }\end{array}$ \\
\hline No warning issued & 881 & 881 \\
\hline Warning issued at the time the dam fails & 333 & 881 \\
\hline 5 minutes before failure & 37 & - \\
\hline 10 minutes before failure & 22 & 333 \\
\hline 15 minutes before failure & 15 & 37 \\
\hline
\end{tabular}




\section{Conclusions}

Earth observation techniques have allowed stakeholders in Peru to monitor tailings dams and save valuable time in the decision making process and sharing of information, thereby reducing the risks posed by tailings storage facilities in the country. Assessment times can be reduced when trying to detect problems and visual inspection programmes can be more informed using the information provided by these techniques. Riskbased approaches to inspection and monitoring of tailings dams based on live EO-based data provide valuable information that complements historical date information, which in most cases is collected from sporadic site inspections that may be out of date.

There is a consensus amongst Peruvian stakeholders that EO-based methods, whilst not a substitute for in situ measurements, can be used by Government authorities to improve dam monitoring and reduce the risks posed by the failures of these structures. The different methods incorporated in the DAMSAT modules can be applied to tailings or water retaining dams anywhere in the world. The methods developed have been piloted on several large tailings dams in Peru and it is expected that the services provided will be expanded to help monitor all the tailings dams in Peru, as well as in other countries. Low income countries, which are often subject to political instability, as many resource-driven economies are, could benefit quickly from many of the EO methods developed as part of this work. The work carried out to date indicates that EO-based monitoring of tailings dams can help decision-making that could help reduce the risks to people and the environment posed by these structures.

\section{Acknowledgments}

The authors acknowledge the work of Dr Eleanor Ainscoe who carried out the analysis of the InSAR data for tailings dams in Peru. The authors also would like to acknowledge that this work was made possible as part of the DAMSAT project, which was funded by a grant from the UK Space Agency's International Partnership Programme. The team working on the project is led by HR Wallingford and comprises Telespazio VEGA UK, Siemens Corporate Technology, Smith School of Enterprise and the Environment at the University of Oxford, Satellite Application Catapult, Oxford Policy Management, Ciemam SAC, Peruvian National Foundation for Hydraulics Engineering, and School of Hydraulic Engineering at the National University of Cajamarca. More information on this work is available from www.damsat.org 


\section{References}

Aguirregabiria, V, Luengo A (2016) A micro-econometric dynamic structural model of copper mining decisions. Available at: http://aguirregabiria.net/wpapers/copper mining.pdf

Agurto-Detzel H, Bianchi M, Assumpção M, Schimmel B, Collaço C, Ciardelli JR, Barbosa J, Calhau J (2016) The tailings dam failure of 5 November 2015 in south-east Brazil and its preceding seismic sequence, Geophys Res Lett 43: 4929-4936, doi:10.1002/2016GL069257

Alexander SS, Dein D, Gold DP (1973) The use of ERTS-1 MSS data for mapping strip mines and acid mine drainage in Pennsylvania. Proc, Symp on Significant Results Obtained from Earth Resources Technology Satellite-1: Vol 1, Sect A: National Aeronautics and Space Administration SP327, pp 569-575

Alonzo M, Van Den Hoek J, Ahmed N (2016) Capturing coupled riparian and coastal disturbance from industrial mining using cloud-resilient satellite time series analysis. Sci Rep-UK 6, 35129. https://doi.org/10.1038/srep35129

Ayee J, Soreide T Shukla GP; Le TM (2011) The political economy of the mining sector in Ghana, Policy research working paper no. WPS 5730. World Bank

Beddington, A, Williams, M (2008) Water and mining conflicts in Peru, Mountain R\&D Vol 28 No 3/4 Aug-Nov 2008: 190-195 doi:10.1659/mrd.1039

Bowker LN, Chambers DM (2016) Root causes of tailings dam overtopping: the economics of risk and consequence. Proc, $2^{\text {nd }}$ International Seminar on Dam Protection against Overtopping, Colorado State Univ, Fort Collins

Bowker LN, Chambers DM (2017) In the dark shadow of the supercycle tailings failure risk and public liability reach all-time highs. Environments 4(4):75; doi:10.3390/environments4040075

Cambridge C, Shaw M (2019) Preliminary reflections on the failure of the Brumadinho tailings dam in January 2019. Dams Reserv 29(3): 113-123

Carlà T, Intrieri E, Di Traglia F, Nolesini T, Gigli G, Casagli N (2017) Guidelines on the use of inverse velocity method as a tool for setting alarm thresholds and forecasting landslides and structure collapses. Landslides 14(2): 517-534, https://doi.org/10.1007/s10346-016-0731-5

Carlà, T, Intrieri, E, Raspini, F, Bardi, F, Farina, P, Ferretti, A, Colombo, D, Novali, F, Casagli, N (2019) Perspectives on the prediction of catastrophic slope failures from satellite InSAR, Sci Rep-UK 9:14137 https://doi.org/10.1038/s41598-019-50792-y

Celik, T (2009) Unsupervised change detection in satellite images using principal component analysis and kmeans clustering. IEEE Geoscience and Remote Sens Letters, Vol. 6, No. 4, October 2009

Chetty, P. (2013) Monitoring of mine tailings using satellite and lidar data, South African Surveying and Geomatics Indaba (SASGI) Proceedings 2013 - Stream 1: http://www.ee.co.za/wp-content/uploads/2014/05/PrevlanChetty.pdf

Condon, M (2017) Citizen science, data transparency and they mining industry Na Res and Env Vol 32, Number 2, Fall 2017

Dale, L (2019) Foiling the resource curse, The Environment Forum, May-June, 2019

Davies, MP (2002) Tailings impoundment failures: are geotechnical engineers listening, Geotechnical News, vol. 20, no. 3, pp31-36 
De Carvalho, DW (2019) The ore tailings dam rupture disaster in Mariana, Brazil 2015: What we have to learn from anthropogenic disasters, Natl Resour J, Vol 59, Issue 2, Summer, 2019

Di Mauro, M, Lumbroso, D (2008) Hydrodynamic and loss of life modelling for the 1953 Canvey Island flood, Proceedings of FLOODrisk 2008, Keble College, University of Oxford, UK, 30 September to 2 October 2008

Franks, DM (2015) Mountain movers: Mining, sustainability and the agents of change, First edition, Routledge

Gamu, J, Le Billon, P, Spiegel, S (2015) Extractive industries and poverty: A review of recent findings and linkage mechanisms, The Extractive Industries and Society, Vol 2, Issue 1, January 2015, pp162-176

Gholizadeh, A, Saberioon, M, Ben-Dor, E, Borůvka, L (2018): Monitoring of selected soil contaminants using proximal and remote sensing techniques: Background, state-of-the-art and future perspectives, Critic Reviews in Environ Sci and Tech, DOI: 10.1080/10643389.2018.1447717

Hejmanowska, B, Glowienka, E, Michalowska, K (2016) Free satellite imagery for monitoring a reclaimed sulphur mining region Tarnobrzeg, Poland, 2016 Baltic Geodetic Congress (BGC Geomatics), Gdansk, 2016, pp. 134-139, doi: 10.1109/BGC.Geomatics.2016.32.

Herrera, G, Tomás, R, Lopez-Sanchez, JM, Delgado, J, Mallorqui, JJ, Duque, S, Mulas, J (2007) Advanced DInSAR analysis on mining areas: La Union case study (Murcia, SE Spain). Eng Geo. 90 (3-4): 148-159. doi:10.1016/j.enggeo.2007.01.001

Hui, S., Charlebois, L, Sun, C (2015) Real-time monitoring for structural health, public safety, and risk management of mine tailings dams, Canadian $\mathrm{J}$ of Earth Sciences Available at: https://tspace.library.utoronto.ca/bitstream/1807/82538/1/cjes-2017-0186.pdf

International Commission On Large Dams (ICOLD) (2001) Tailings dams: Risk of dangerous occurrences, lessons learnt from practical experiences, United Nations Environmental Programme (UNEP), Division of Technology, Industry and Economics (DTIE) and International Commission on Large Dams (ICOLD), Paris, France, Bulletin 121, 2001

Johnstone, WM (2012) Life safety modelling framework and performance measures to assess community protection systems: Application to tsunami emergency preparedness and dam safety management, Doctor of Philosophy, University of British Columbia, Canada, October, 2012

Keaveny, P. (2019) Brumadinho dam collapse: Mining industry needs radical change to avoid future disasters, 8 March 2019, The Conversation, available at: https://theconversation.com/brumadinho-dam-collapse-miningindustry-needs-radical-change-to-avoid-future-disasters-112808

Ledwaba, P and Nhlengetwa, K (2016) When policy is not enough: prospects and challenges of artisanal and small-scale mining in South Africa, J of Sus Dev Law and Policy, Vol 7, No 1 (2016) /African Journals On Line

Leonard, L (2017) State governance, participation and mining development: Lessons learned from Dullstroom, Mpumalanga, Politikon, South African J of Politic Studies Vol 44, 2017 - Issue 2

Lumbroso, D, Sakamoto, D, Johnstone, WM, Tagg, AF, Lence, BJ (2011) The development of a Life Safety Model to estimate the risk posed to people by dam failures and floods, Dams and Reservoirs, The official $\mathrm{J}$ of the British Dam Society, Vol 21, Issue 1, pp31-43, June 2011

Lumbroso, D, Tagg, A (2011) Evacuation and loss of life modelling to enhance emergency response, published in the proceedings of the International Symposium on Urban Flood Risk Management Graz, Austria, 21-23 September 2011 
Lumbroso, D, Davison, M (2018) Use of an agent-based model and Monte Carlo analysis to estimate the effectiveness of emergency management interventions to reduce loss of life during extreme floods, J of Flood Risk Manage, Vol 11, Issue S1, January 2018, ppS419-S433

Lumbroso, D, McElroy, C, Goff, C, Collell, M, Petkovšek, G, Wetton, M (2019) The potential to reduce the risks posed by tailings dams using satellite-based information, Int J of Disaster Risk Reduction. ISSN: 2212-4209, Vol38, August 2019

Lumbroso, D, Davison, M, Body, R, Petkovšek, G (2020) Modelling the Brumadinho tailings dam failure, the subsequent loss of life and how it could have been reduced, submitted, Nat Hazards and Earth Sys Sci https://www.nat-hazards-earth-syst-sci-discuss.net/nhess-2020-159/

Marcuccio, S, Ullo, S, Carminati, M, Kanoun, O (2019) Smaller satellites, larger constellations: Trends and design issues for earth observation systems, IEEE Aerospace and Electronic Systems Magazine. 34. 50-59. 10.1109/MAES.2019.2928612

Martin, TE, Davies, MP (2000) Development and review of surveillance programs for tailings dams, AGRA Earth and Environmental Limited, Burnaby, British Columbia, Canada http://citeseerx.ist.psu.edu/viewdoc/download?doi=10.1.1.520.7963andrep=rep1andtype=pdf

Martin, TE, McRoberts, EC (1999) Some considerations in the stability analysis of upstream tailings dams in Proceedings of Sixth International Conference on Tailings and Mine Waste '99, $24-27$ January 1999, Fort Collins, Colorado, USA

McDevitt, A (2017) Transparency and accountability initiatives in the extractives sector, K4D Helpdesk Report. Brighton, UK: Institute of Development Studies.

https://assets.publishing.service.gov.uk/media/59784da140f0b65dce000002/082-Transparency-andaccountability-in-extractive-industries.pdf

Mohamed, MAAH., Samuels, PG, Morris, MW, Ghataora, GS (2002) Improving the accuracy of prediction of breach formation through embankment dams and flood embankments. Proceedings of the international conference on fluvial hydraulics (Riverflow 2002), 3-6 September 2002. Louvainla- Neuve. Belgium

Minerals Policy Institute (2014) Chronology of major tailings dam failures - Updated with Mount Polley, 7 August 2014, available at: https://www.mpi.org.au/2014/08/chronology-of-major-tailings-dam-failures/

Mining Journal (2019) Tailings spill at Doe Run's Cobriza mine, https://www.mining-journal.com/coppernews/news/1367271/tailings-spill-at-doe-runs-cobriza-mine

Mining Journal (2020) March underway to Brumadinho to mark year since fatal dam collapse, 21 January 2020 , available at: https://www.mining-journal.com/politics/news/1379365/march-underway-to-brumadinho-to-markyear-since-fatal-dam-collapse

Morris, MW (2011) Breaching of earth embankments and dams. PhD thesis, The Open University, UK

Mulaba-Bafubiandi, AF, Singh, N (2018) Junior mining as innovation entrepreneurship in minerals industry in South Africa in Proceedings of the International Conference on Industrial Engineering and Operations Management Pretoria / Johannesburg, South Africa, 29 October to 1 November 2018

Nishijima, M, Rocha, FF (2020) An economic investigation of the dengue incidence as a result of a tailings dam accident in Brazil, J of Enviro Manage, 253, art. no. 109748;

O'Neill, S. (2019) A machine learning revolution in disaster response, The Alan Turing Institute, available at: https://www.turing.ac.uk/research/impact-stories/machine-learning-revolution-disaster-response 
Palú, MC, Julien, PY (2019) A review of tailings dam failures in Brazil, 24 to 28 November 2019, Conference: XXIII Simpósio Brasileiro De Recursos Hídricosat: Foz do Iguaçú, Brazil, 2019

Petkovšek, G, Hasan, MAAH., Lumbroso, D, Roca Collell, M (2020) A two-fluid simulation of tailings dam breaching, submitted, Mine Water and the Environ, J of the Intl Mine Water Assoc (IMWA)

Petley, D (2019) Cobriza, Peru: Another significant tailings dam failure, American Geophysic Union (AGU), 16 July 2019 available at: https://blogs.agu.org/landslideblog/2019/07/16/cobriza-mine-1/

Sachs, JD, Warner, AM. (2001) The curse of natural resources. European economic review, 45(4), 827-838

Scaioni, M, Marsella, M, Crosetto, M, Tornatore, V, Wang, J (2018) Geodetic and remote-sensing sensors for dam deformation monitoring, Sensors 2018, 18, 3682

Seifi A, Hosseinjanizadeh M, Ranjbar H, and Honarman M (2019) Identification of acid mine drainage potential using Sentinel 2a imagery and field data. Mine Water and the Environment 38:707-717, https://doi.org/10.1007/s10230-019-00632-2

Sonwalkar, M, Fang, L, Sun, D (2010) Use of NDVI dataset for a GIS based analysis: A sample study of TAR Creek superfund site, Ecol Inform, Vol 5, Issue 6, November 2010, pp484-491

Thomas, A; Edwards, SJ; Engels, J; McCormack, H; Hopkins, V, Holley, R; (2019) Earth observation data and satellite InSAR for the remote monitoring of tailings storage facilities: a case study of Cadia Mine, Australia. in: Paterson, AJC and Fourie, AB and Reid, D, (eds.) Proc of the 22nd International Conference on Paste, Thickened and Filtered Tailings. pp183-195, Australian Centre for Geomechanics (ACG), The Univ of Western Australia: Perth, Australia

Tomás, R, Romero, R, Mulas, J, Marturià, JJ, Mallorquí, JJ, Lopez-Sanchez, JM, Herrera, G, Gutiérrez, F, González, PJ, Fernández, J, Duque, S, Concha-Dimas, A, Cocksley, G, Castañeda, C, Carrasco, D, Blanco, P (2014) Radar interferometry techniques for the study of ground subsidence phenomena: A review of practical issues through cases in Spain Environ Earth Sci. 71: pp163-181

Tre-Altimira (2018) Tailings dam failure Available at: https://site.tre-altamira.com/showcase/tailings-dam-failure/

United Nations (UN) (2017) Earth observations for official statistics, Satellite imagery and geospatial data task team report, 5 December 2017 https://unstats.un.org/bigdata/taskteams/satellite/UNGWG Satellite Task Team Report WhiteCover.pdf

Van der Werff, H, Van der Meer, F (2015). Sentinel-2 for mapping iron absorption feature parameters. Remote Sens 7, 12635-12653. doi.org/10.3390/rs71012635

Vergilio, C, Lacerda, D, Oliveira, B, Sartori, É, Campos, G, Pereira, A, Aguiar, D, Souza, T, Almeida, M, Thompson, F, Rezende, C (2020) Metal concentrations and biological effects from one of the largest mining disasters in the world (Brumadinho, Minas Gerais, Brazil). Sci Rep. 10. 10.1038/s41598-020-62700-w.

Vick, S (1990) Planning, design, and analysis of tailings dams, Published by BiTech, Vancouver, Canada, ISBN: 978-0921095125

Xiao, R, Shi, H, He, X, Li, Z, Jia, D, Yang, Z (2019) Deformation monitoring of reservoir dams using GNSS: An application to south-to-north water diversion project, China in IEEE Access, vol. 7, pp. 54981-54992, 2019 